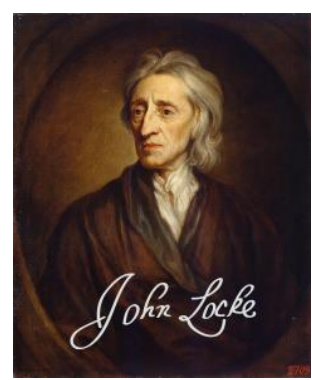

LOCKE STUDIES

Vol. 17

https://doi.org/10.5206/ls.2017.873 | ISSN: 2561-925X

Originally published: 2017

Published online: 01 JANUARY 2019

(c) Locke Studies, 2017

\title{
Locke on Individuation and Kinds
}

JOSEPH STENBERG (HUMBOLDT-UNIVERSITÄT ZU BERLIN)

Recommended citation:

Stenberg, Joseph. "Locke on Individuation and Kinds." Locke Studies 17 (2017): 87-116.

https://doi.org/10.5206/ls.2017.873.

For more information about this article:

see this article's webpage.

Locke Studies is published by The John Locke Society.

This is an open access article published under the terms of the Creative Commons AttributionNonCommercial-ShareAlike 4.0 International license, which permits use, distribution and reproduction in any medium, provided the original work is properly cited and shared under the original license. 


\title{
LOCKE ON INDIVIDUATION AND KINDS
}

\author{
JOSEPH STENBERG
}

\begin{abstract}
Locke has been accused of endorsing a theory of kinds that is inconsistent with his theory of individuation. This purported inconsistency comes to the fore in Locke's treatment of cases involving organisms and the masses of matter that constitute them, for example, the case of a mass constituting an oak tree. In this essay, I argue that this purported problem, known as 'The Kinds Problem', can be solved. The Kinds Problem depends on the faulty assumption that nominal essences include only features observable at a time $t$. Once this assumption is rejected, new candidates open up for the relevant difference in the world that is included in the nominal essence of e.g. mass but not oak tree. And I argue that there is at least one good candidate for the extrinsic feature observable only over time in which the mass differs from the oak it constitutes, namely its persistence conditions. The Kinds Problem can be solved. ${ }^{1}$
\end{abstract}

\section{Keywords}

Kinds, Individuation, Locke, Kinds Problem, Nominal Essence, Persistence.

An oak tree grows outside my window. I watch a few leaves fall off in a gust of wind. Two things seem true after the leaves break away from the rest of the tree. First, it seems the oak tree lost quite a host of particles and so the tree is no longer constituted by the same mass of particles. Second, it seems the oak tree is still numerically the same oak tree.

Locke tries to preserve both appearances by arguing that one tree can be constituted by two different masses at two different times. Thus, although at any given time the mass and the organism are constituted by the very same particles, the mass and the organism, in some sense, are not identical.

It seems that we owe William Molyneux special thanks for

${ }^{1}$ As I take him, then, Locke's view in this regard is similar to the way in which some try to individuate material objects by their location in space, in that both views appeal to extrinsic features of a thing to explain the sense in which that thing is importantly different from other things. 
prompting Locke's attempt at providing an explanation that reconciles these appearances. The chapter in which that explanation appears, 'Of Identity and Diversity' ( $E$ II.xxvii), was not included in the first edition of the Essay, nor was the topic covered in any of the drafts of the Essay. ${ }^{2}$ And Locke writes to Molyneux that he composed the chapter 'only at your instance'. 3 Since the chapter seems to have been written only at the behest of Molyneux, and written quickly (from March to August 1693), it is perhaps unsurprising that this chapter and the way it fits (or doesn't fit) with the rest of the Essay provokes the interest and ire of commentators. ${ }^{4}$

One thing that is generally agreed upon by commentators is that whatever Locke takes his explanation of the mass-oak case to be in this chapter, it depends crucially on the notion of kinds. This is so because Locke's basic principles concerning individuation and related issues depend crucially on the notion of kinds, and the mass-oak case fundamentally involves individuating (or picking out as importantly different) the mass and the oak tree. Of particular importance here is the principle which states that it is impossible 'that two things of the same kind should exist in the same place at the same time' (E II.xxvii.1); this principle is known as the Place-Time-Kind Principle. So most interpreters of Locke agree that the way to make sense of Locke's treatment of the mass-oak case is to appeal to some difference in kind between the mass and the oak tree.

But from this initial agreement proceeds a cacophony of disagreement over what Locke meant by the term 'kind' in the Place-Time-Kind Principle. There are three main approaches, none of them without well-documented, and difficult, interpretive

${ }^{2}$ For information about the drafts of the Essay, see the introduction to Locke (1990).

${ }^{3}$ Locke (1976) vol. 4, letter 1655, p. 722, 'instance' meaning 'urging' or 'entreaty'. See $O E D$, 'instance' I, 1 , a.

${ }^{4}$ Molyneux's letter asking for a chapter on the principium individuationis is dated 2 March 1693 and Locke sent the chapter to Molyneux with a letter on 23 August 1693. 
issues. ${ }^{5}$ Because the approaches and problems with each are familiar, I will explain each approach only briefly.

The first is the Material-Immaterial Substance reading, according to which 'kind' picks out three and only three different sorts of substances: material substances (or bodies), immaterial substances (or minds), and God. Read in this way, the principle holds e.g. that no two material substances can be in the same place at the same time, but a material substance and an immaterial substance could be in the same place at the same time. ${ }^{6}$

The second is the Simple-Compounded Substance reading, according to which, roughly, 'kind' refers not only to the difference between the three sorts of substances outlined above, but also to the difference between a substance that can endure the loss of its parts (a compounded substance) and a substance that cannot endure the loss of its parts (a simple substance). According to this reading, then, when understood in the relevant sense, a compounded substance and a simple substance can be in the same place at the same time, even should the two substances in question be material. For example, an oak tree is a compounded substance, in the relevant sense, whereas a mass of

${ }^{5}$ For an excellent discussion of these three main approaches as well as the main problems associated with them, see Jessica Gordon-Roth (2015). In this brief discussion here, I rely heavily on that paper.

${ }^{6}$ The following commentators have defended this reading: Harold Noonan (1978), William Uzgalis (1990), Antonia LoLordo (2010, 2012), Matthew Stuart (2013), Martha Brandt Bolton (2014), and Edwin McCann (2014).

If one accepts the Material-Immaterial Substance reading, one problem that must then be addressed is how it can be that, say, an oak tree and the mass that constitutes it can be in the same place at the same time. After all, both an oak tree and the mass that constitutes it seem to be material substances, but they are in the same place at the same time. Among the solutions offered to this problem are that organisms, like oak trees, are modes and not substances in their own right (Uzgalis (1990)); that Locke is a relative identity theorist and so thinks that, strictly speaking, when dealing with organisms, say, there is one material substance that we catalog in two ways (Noonan (1978) and Stuart (2013)); and, finally, that Locke is a four-dimensionalist and so treats the mass as a temporal part of a temporally extended oak tree (Christopher Conn (1999 and 2003)). None of these views is without further difficulties to address, although considering them each in turn would take us too far afield. Jessica Gordon-Roth's Philosophy Compass paper is a good place to start for those interested in considering these further difficulties for each interpretive route. 
matter is a simple substance, in the relevant sense. So, if 'kind' in the principle tracks the difference between compounded substances and simple substances and not just the difference between material and immaterial substances, an oak and the mass that constitutes it can be in the same place at the same time. ${ }^{7}$

The third is the Nominal Essence reading, according to which, 'kind' refers to nominal essences or species. ${ }^{8}$ If this reading is correct, then because oak trees and the masses that constitute them have different nominal essences we can affirm that the oak and mass constituting it can be in the same place at the same time.

In this essay, it is the most difficult problem with this third and final reading that I take up: the charge that, on the Nominal Essence reading, Locke's views on individuation and kinds are inconsistent. Anything like a full defense of any of these readings would take us too far afield - to say nothing of an attempted refutation of the others. So I will not defend the Nominal Essence reading in any thoroughgoing fashion. However, in Section 1 below, I briefly motivate that account, since the historical interest of what follows depends upon taking that account seriously as an interpretive option. Now, even if one ultimately prefers some other reading of the historical Locke, it seems to me that more general and quite interesting philosophical issues are raised in considering how someone with broadly Lockean sympathies may respond to this charge.

7 The main defenders of the Simple-Compounded Substance reading have been Chappell (1990) and Bolton (1994); however, Bolton has recently joined the MaterialImmaterial camp (2014).

A difficult problem for the Simple-Compounded Substance reading is raised by Dan Kaufman (2007): 'I...don't think that Bolton's [Simple-Compounded Substance] interpretation is right. Locke's clearest examples of simple substances are atoms, God, and finite intelligences. I think that these examples indicate that Locke held a quasimereological account of simplicity, i.e., $\mathrm{x}$ is simple iff $\mathrm{x}$ is without naturally separable proper parts (i.e., iff $\mathrm{x}$ is naturally indivisible into proper parts). Now clearly masses are not simple in that sense. In fact, masses are compounded things par excellence. In order for Bolton's interpretation to work, there must be a sense of 'simple' such that masses are simple but organisms are not. I am just not sure what sense can be made of this' (p. 506, fn. 21).

8 The two most prominent defenders of this reading are Dan Kaufman (2007) and Yaffe (2007). 
The problem for this third reading is that Locke's theory of kinds, where 'kinds' refer to nominal essences, seems to entail that the mass and the oak tree it constitutes cannot be of different kinds, even while the Nominal Essence reading of the PlaceTime-Kind Principle seems to entail that the mass and the oak tree it constitutes must be of different kinds. If this is correct, then obviously there's a problem: Locke's views on individuation and kinds are inconsistent. This problem is known as, 'The Kinds Problem'. ${ }^{9}$

According to Locke's general theory of kinds, a kind term, like 'oak tree', is introduced by a linguistic community to pick out a class of phenomena that have some set of shared characteristics by which the phenomena can be grouped; that set of shared characteristics associated with the kind term is a nominal essence..$^{10}$ It is important to note that, at least with respect to material things, this way of thinking about kind terms preserves a role both for linguistic communities and also a role for the world. ${ }^{11}$ A linguistic community is, as it were, constrained by the raw material of the world, in that there is a fixed set of phenomena from which the community can pick out sets of shared characteristics. For example, particular oak trees themselves provide a kind of raw material of features to a linguistic community and the linguistic community then picks out which of the features produced by particular oak trees to include in the nominal essence associated with the kind term, 'oak tree'.

So it seems that the mass and oak tree cannot be of different kinds, given Locke's theory of kinds, because he holds that kinds

${ }^{9}$ The Kinds Problem, or something like it, is noted at least in passing by Uzgalis (1990), Winkler (1991), Bolton (1994), and Kaufman (2007). Kaufman has developed the problem most forcefully and so my reconstruction of the problem centers on his formulation.

10 There are, of course, disputes about how to take Locke's views on language, meaning, etc. I will try to present the problem in such a way that it hangs on nothing controversial. For a brief survey of interpretations and a discussion of Locke's views on these matters, see Losonsky (2007).

${ }^{11}$ Locke holds nominal essences are the 'Workmanship of the Understanding'. E III.iii.14. 
depend on the internal structure of individuals in the world for the raw material included in their nominal essences inasmuch as internal structures produce the discoverable qualities included in the nominal essences associated with kind terms. ${ }^{12}$ So, if an observable feature is a candidate for inclusion in the nominal essence of a class of material things, that is ultimately because those material things all have internal structures that produce that observable feature, whether the internal structures of those things are similar or not. ${ }^{13}$

Now, applied to the case of the mass and oak tree, at any given time the internal structure of the mass and the oak tree that it constitutes are not merely similar, they are numerically identical. So because all the observable features of a thing are ultimately produced by the internal structure of a thing and the mass and oak have the very same internal structure, the mass and the oak have the same set of observable features at any given time. But the observable features of a thing are the potential ingredients in the nominal essence of that thing. So it seems that the oak tree and the mass that constitutes it cannot have different nominal essences because, at a time, if one of them has a feature, $x$, then so too does the other. In other words, there is no feature that the oak tree has at a time that the mass lacks and vice versa. And given that a kind-term picks out a nominal essence and given that the nominal essence of an oak cannot differ from that of the mass that constitutes it because the mass and oak always have the same

${ }^{12}$ E II.xxiii.3, II.xxxi.6, III.iii.15, III.iii.17, and Locke (1824): III, 91.

${ }^{13}$ Locke believes that we cannot confidently hold that when things have the same observable properties they must have the same internal structure. He says at Essay 3.10.20 that human beings assume 'that Nature works regularly in the Production of Things, and sets the Boundaries to each of those Species, by giving exactly the same real internal Constitution to each individual, which we rank under one general name'. But he thinks 'any one who observes their different Qualities can hardly doubt, that many of the Individuals, called by the same name, are, in their internal Constitution, as different from another, as several of those which are ranked under different specifick Names'.

Of course, if the feature in question (as is often the case) is a secondary quality, the way the internal structure interacts with another body (say, normal human bodies) will also be a relevant causal factor in the sorts of features that might be included in a nominal essence. 
set of features, the oak and the mass cannot be of different kinds.

There is considerable dispute about how to interpret Locke's distinction between the oak tree and its mass, but it has been claimed that the Kinds Problem is intractable for all of them. ${ }^{14}$ This, however, seems to be an overstatement of the scope of the Problem. For it seems that the Kinds Problem will only arise if we accept the Nominal Essence reading of Locke's Place-TimeKind Principle.

Take, for example, one development of the MaterialImmaterial Substance reading: what's known as the 'relativeidentity interpretation'. According to this interpretation, the mass and oak don't differ in reality, but only in how we think about one and the same thing in the world. If we take them to differ only in our minds, then the mass and oak (and not just their internal structures) are numerically identical out in the world and the mass and oak differ only inasmuch as we think of each as having different features. And if they differ only inasmuch as we think of each as having different features, then we can consistently claim that the mass and oak have different nominal essences (and so are of different kinds) and that the features included in those nominal essences ontologically depend on the internal structure that the mass and oak share. To see this, for simplicity's sake, say that right now the oak-mass outside my window produces three observable features: $\mathrm{x}, \mathrm{y}$, and $\mathrm{z}$. Say that $\mathrm{x}$ and $\mathrm{y}$ are associated with the kind, mass, and $\mathrm{y}$ and $\mathrm{z}$ are associated with the kind, oak. The two have different nominal essences (because different observable features are included in the nominal essence of each) and so the one individual falls under two different kinds. And that claim is entirely consistent with the claim that $\mathrm{x}, \mathrm{y}$, and $\mathrm{z}$ ontologically depend on the internal structure that the mass and oak share. So given this interpretation of Locke, the Kinds Problem does not arise. ${ }^{15}$ And it seems to me that the Kinds Problem need not arise for defenders of other versions of the

\footnotetext{
${ }^{14}$ Kaufman (2007): 500.

${ }^{15}$ For a thorough defence of this view, see Stuart (2013).
} 
Material-Immaterial Substance interpretation, or for defenders of the Simple-Compounded Substance reading. However, again, these views are not without their own serious problems.

Notice that a similar move cannot be made on the Nominal Essence reading, according to which the mass and oak differ out in the world, but still manage to be in the same place at the same time. ${ }^{16}$ Let's assume that the mass, M, and the oak constituted by that mass, O, differ out in the world; that is, let's assume that, although $\mathrm{M}$ and $\mathrm{O}$ share an internal structure at a time, $\mathrm{M}$ is not numerically identical to $O$. And let's say, again, that right now the internal constitution shared by $\mathrm{M}$ and $\mathrm{O}$ outside my window produces observable features $\mathrm{x}, \mathrm{y}$, and $\mathrm{z}$. Say we try the same strategy used above: the kind, mass, is associated with features $\mathrm{x}$ and $\mathrm{y}$ whereas oak is associated with $\mathrm{y}$ and $\mathrm{z}$. Why won't this work?

The reason is that $\mathrm{M}$ and $O$ would fall under the kind, mass, and $\mathrm{O}$ and $M$ would fall under the kind, oak. This is so because $\mathrm{x}$, $\mathrm{y}$, and $\mathrm{z}$ are all features of both $\mathrm{O}$ and $\mathrm{M}$. If $\mathrm{O}$ and $\mathrm{M}$ have all the same observable features, then there is no kind that $\mathrm{O}$ could fall under that $\mathrm{M}$ would not also fall under. So $\mathrm{O}$ and $\mathrm{M}$ cannot be of different kinds. If $\mathrm{O}$ and $\mathrm{M}$ cannot be of different kinds, thengiven Locke's principles of individuation-we cannot affirm that $\mathrm{O}$ and $\mathrm{M}$ are in the same place at the same time. But we have to be able to affirm that $\mathrm{O}$ and $\mathrm{M}$ are in the same place at the same time, given Locke's treatment of the mass-oak case. Therefore, if $\mathrm{M}$ and $\mathrm{O}$ differ out in the world, Locke's views on individuation are inconsistent with his theory of kinds. That is, The Kinds Problem is a genuine problem.

So, although I don't think the Kinds Problem is on its face intractable for every interpretation of Locke's theory of indiviuation, it seems intractable for those who accept the

\footnotetext{
16 This is an important respect in which the Nominal Essence reading is connected to a different background picture of the mass-oak case than, say, the MaterialImmaterial Substance reading. As it has been defended in the literature, the Nominal Essence reading is deeply connected to the coincident object reading of the mass-oak case-see Kaufman (2007). Chappell $(1989,1990)$ is the principal defender of the coincident object reading.
} 
Nominal Essence reading of Locke's Place-Time-Kind Principle. However, in this essay, I argue that The Kinds Problem is not, in fact, intractable, even on the Nominal Essence reading.

More specifically, I argue that a Lockean theory of kinds and a Lockean theory of individuation, understood in Nominal-Essence terms, are consistent. I argue that this is so because, given Locke's view of nominal essences, extrinsic or relational features only observable over time can be included in nominal essences. The Kinds Problem depends on the assumption that nominal essences include only features observable at a time. This assumption is false. Given that it is false, new candidates open up for the relevant difference in the world that is included in the nominal essence of mass, but not oak tree. And there is at least one good candidate for the extrinsic or relational feature observable only over time in which the mass differs from the oak it constitutes, namely, its persistence conditions. And so I argue that Locke at least could, and perhaps did, include the persistence conditions of things like masses and oak trees in the nominal essences, mass and oak tree. The mass and the oak constituted by that mass outside my window really do differ and this difference is included in the nominal essences of both. Thus the mass and oak differ in kind and so can be in the same place at the same time, even though at a time they share the very same internal structure. $^{17}$

The remainder of this paper is broken down into three sections. In the first, I very briefly motivate the Nominal Essence reading of the Place-Kind-Time Principle. In the second section, I set out the Kinds Problem more carefully. In the final section, I lay out the solution to the Kinds Problem.

\section{\$1. Motivating the Nominal Essence Reading}

The goal of this brief section is not to convince anyone that we ought to read 'kind' in the Place-Time-Kind Principle as a

${ }^{17}$ Again, as I take him, then, Locke's view in this regard is similar to the way in which some try to individuate material objects by their location in space, in that both views appeal to extrinsic features of a thing to explain the sense in which that thing is importantly different from other things. 
reference to nominal essences. Rather, I aim to motivate readers to take this reading seriously as a possible account of what Locke himself was up to. The project of determining, all things considered, the best reading of this principle is certainly worthwhile and it is a wider debate to which I hope to contribute by showing that a purported problem with one reading isn't in fact a problem. ${ }^{18}$ However, anything approaching a full defense of this reading would take us too far afield.

The positive case in favor of the Nominal Essence Reading is best developed as a kind of cumulative textual case. ${ }^{19}$ The first part of that case involves drawing attention to passages in $E$ II.xxvii itself in which Locke clearly draws our attention to the importance of nominal essences in individuating things that are often found together. For example, Locke says:

'Tis not therefore Unity of Substance that comprehends all sorts of Identity, or will determine it in every Case: But to conceive, and judge of it aright, we must consider what Idea the Word it is applied to stands for: It being one thing to be the same Substance, another the same Man, and a third the same Person, if Person, Man, and Substances, are three Names standing for three different Ideas; for such as is the Idea belonging to the Name, such must be the Identity ( $E$ II.xxvii.7)

In this passage, 'idea' clearly refers to a nominal essence. And an implication of the passage seems to be that there is no serious problem with something's being simultaneously a substance, a man, and a person because these are three different kinds of things. But if that is so, then it is plausible to think that 'kind' in the Place-Kind-Time Principle refers to nominal essences, since the kinds referred to in this passage are clearly nominal essences. Mutatis mutandi, the same can be said of Locke's account of the mass-oak case itself. And so II.xxvii provides good reason for thinking that we should read 'kind' in the Place-Time-Kind

${ }^{18}$ For those interested in this wider debate, see Gordon-Roth (2015).

${ }^{19}$ What follows in this section is a rehearsal of the case put forward by Dan Kaufman (2007). I take it that he is the most forceful defender of this view. Another less forceful defender of the view is Gideon Yaffe. See Yaffe (2007). 
Principle as referring to nominal essences.

But evidence in favor of this reading can also be drawn from material elsewhere in the Essay. It has been convincingly argued that Locke's theory of kinds in the Essay is a theory of nominal essences - the next section of the paper rehearses some of that argument. ${ }^{20}$ It seems plausible to think that that theory should be read into the Place-Kind-Time Principle, since it is Locke's considered view about kinds and, as we have seen, reading 'kind' in that way makes good sense of some of the examples that Locke explicitly uses later in II.xxvii.

Of course much more can be and has been said in defence of the Nominal Essence Reading of Locke. ${ }^{21}$ But I hope this very brief overview is enough to make it clear that the Nominal Essence Reading is a live interpretive option. Moving forward, then, I take it for granted that, as a historical project, a solution to the Kinds Problem is worth seeking.

\section{§2: The Kinds Problem}

The Kinds Problem holds that Locke is committed to the claim that (1) the mass and oak tree it constitutes are of different kinds and to the claim that (2) the mass and the oak tree it constitutes cannot be of different kinds. The former claim is secured by the Nominal Essence reading of Locke's Place-Time-Kind Principle. The latter claim is secured by way of an analysis of Locke's theory of kinds. Since I am assuming that the Nominal Essence reading is correct, in what follows I will do more to motivate and carefully set out the Kinds Problem by focusing on why Locke seems to be committed to the second of these claims. ${ }^{22}$

There are two key principles that Locke apparently accepts that make it seem undeniable that the mass and the oak tree it constitutes cannot be of different kinds. First, nominal essences specify the content of kind terms. Second, nominal essences

${ }^{20}$ Kaufman (2007).

${ }^{21}$ I point the interested reader to Kaufman (2007) for a fuller defense of this reading.

${ }^{22}$ In this section of the paper, I will be relying heavily on Kaufman (2007). 
associated with material objects are formed by abstracting features that depend on the internal structures of those objects. I will note some of the most important evidence that strongly suggests Locke is committed to these claims.

Locke's first presentation of the distinction between real and nominal essences helps make it clear that nominal essences specify the content of kind terms. In introducing the notion of a nominal essence he says:

Things are ranked under Names into sorts or Species, only as they agree to certain abstract Ideas, to which we have annexed those names, the Essence of each Genus, or Sort, comes to be nothing but that abstract Idea, which the General, or Sortal...Name stands for. (E III.iii.15)

So, a nominal essence ('Essence' in the passage quoted) just is the general idea that a general name stands for. General ideas are those that by 'way of abstraction...are made capable of representing more Individuals than one' ( $E$ III.iii.6). Kind terms are the paradigm case of general ideas. And so general names, like 'oak tree' and 'mass', stand for nominal essences.

Now to the claim that Locke accepts the second principle: nominal essences associated with material objects are formed by abstracting features that depend on the internal structures of those objects. Locke affirms that there is a 'real internal, but generally in Substances, unknown Constitution of Things, whereon their discoverable Qualities depend' ( $E$ III.iii.15). This real internal constitution may be called the 'essence' of a thing and we use the term 'essence' in this sense 'when we speak of the Essence of particular things, without giving them any Name' (III.iii.15). In other words, prior to our naming things, particular things have discoverable features that ontologically depend on the internal structure of those particular things. It seems that by 'internal structure' Locke has in mind the corpuscularianism of his day, which holds that the microphysical structures of things - the 'insensible Parts' (III.iii.17)-ultimately explain all the observable features that things have. At the very least, it seems clear that Locke wants his view on these matters to be consistent 
with corpuscularianism, since it was the best theory available at the time. So, according to Locke, the observable features of material objects depend on the internal structures of those objects. This gets us half way to the second principle.

The second half of the principle suggests that nominal essences associated with material objects are formed by abstracting a set of shared features from a set of material objects. In other words, it suggests that we form general ideas concerning material objects by noticing natural or objective similarities between particular material objects. And then, leaving out dissimilarities and similarities we think are irrelevant, we fuse together a set of simple ideas into a general kind idea that captures what is, by our lights, importantly shared by that set of things. ${ }^{23}$ This movement from the whole set of objective similarities to a subset of importantly shared objective similarities is the process of abstracting. And, on Locke's view, it is by way of this process that we form general ideas.

That this is Locke's view seems clear. ${ }^{24} \mathrm{He}$ says, '[W]e come to have the Ideas of particular sorts of Substances, by collecting such Combinations of simple Ideas, as are by Experience and Observation of Men's Senses taken notice of to exist together, and are therefore supposed to flow from the particular internal Constitution, or unknown Essence of that Substance' ( $E$ II.xxiii.3). So, for example, "Tis the ordinary Qualities, observable in Iron, or a Diamond, put together, that make the true complex Idea of those Substances' (II.xxiii.3 again). And in another telling statement he says:

I would not here be thought to forget, much less to deny, that Nature in the Production of Things, makes several of them [particulars] alike: there is nothing more obvious, especially in the Races of Animals, and all Things propagated by Seed. But yet, I think, we may say, the sorting of them under Names, is the Workmanship of the Understanding, taking occasion from the similitude it observes amongst them, to make abstract general

${ }^{23}$ For example, the kind, gold, includes the simple ideas Yellowness, dissolvability in aqua regia, etc. (Essay II.xxiii.10).

${ }^{24}$ See E II.xxiii.3; II.xxiii.11; III.1ii.12; III.iii.17; and Conn (2002): 480. 
Ideas, and set them up in the mind, with Names annexed to them, as Patterns, or Forms. (E III.iii.13)

Taken together, these two passages strongly suggest that Locke accepts the picture the second principle ascribes to him. ${ }^{25}$ There are objective similarities between things in nature because the internal structures of things generate similar observable features. Humans bring to the world the ability to sort things on the basis of similarities and differences. When confronted with what seem to be importantly similar things, humans form nominal essences that include the set of important, shared features. And they introduce names to associate with those nominal essences.

So it seems that Locke accepts both of these principles: (1) nominal essences specify the content of kind terms and (2) nominal essences associated with material objects are formed by abstracting features that depend on the internal structures of those objects. But if he does, then it seems Locke is forced to say that the mass and oak tree cannot differ in kind. For at any given time, the mass, $\mathrm{M}$, and oak, $\mathrm{O}$, produce the very same set of observable features because (by principle 2) observable features are generated by internal structures and the mass and oak share a numerically identical internal structure; after all, the mass constitutes the oak tree. But observable features are the ingredients in nominal essences (by principle 2). So it seems that whatever nominal essence applies to $\mathrm{M}$ must apply to $\mathrm{O}$ and vice versa; in other words, the mass, $\mathrm{M}$, and oak tree, $\mathrm{O}$, cannot differ with respect to the nominal essences that apply to them. And thus they cannot differ with respect to their kinds (by principle 1). But, according to the Place-Time-Kind Principle, they must be of different kinds, since they are in the same place at the same time.

So it seems Locke is saddled with The Kinds Problem. He cannot save the dual appearances with which I started the paper; it can't be the case that the oak tree is constituted by a different mass, but remains numerically the same oak tree. For he cannot appeal to a difference in kind to make sense of how the oak tree

${ }^{25}$ There are, of course, other passages that support this reading. See, for example, $E$ II.xxiii.11, III.iii.12, and III.iii.17. 
can exist in the same place at the same time as the mass and then endure through some change that the mass can't. So, unless there is some solution to the Kinds Problem, on the Nominal Essence reading, Locke offers us no coherent way of making sense of appearances in cases like that of the mass and oak, which he obviously aims to do; his views on individuation and kinds are inconsistent.

\section{§3: The Solution to the Kinds Problem}

In this section, I intend to show that, even on the Nominal Essence reading of the Place-Time-Kind Principle, Locke's theory of kinds and his theory of individuation are not in principle inconsistent and, further, to give reason to believe that Locke himself did not hold inconsistent views on this matter. And so I intend to show that he could, or perhaps did, consistently hold that (1) a mass at any given time has precisely the same internal structure as the oak tree the mass constitutes at that time and that (2) the mass is not of the same kind as the oak tree at any given time.

The crux of the solution is the claim that the Kinds Problem doesn't take into account the sorts of features that Locke includes in nominal essences. So the Kinds Problem only arises because it unnecessarily restricts the sorts of features included in nominal essences to those observable at a time. Ultimately, I will argue that it is open to Locke to include different features observable only over time into the nominal essences of mass and oak tree, namely, the persistence conditions of each. ${ }^{26}$ If I can show that this is possible on Locke's account, even within the strictures set out above concerning the causal role of internal structures in generating the ingredients of nominal essences, then I will have

${ }^{26}$ I am not the first commentator to argue that persistence conditions are (at least often) included in nominal essences. For example, Matthew Stuart says, it 'does seem to be [Locke's] view that the persistence conditions that govern things of a kind are built into the nominal essence that defines the kind' (2013: 333). However, no commentator of whom I am aware has further argued that the fact that persistence conditions can be included in the nominal essences of things can play an important part in a solution to the Kinds Problem. And that seems an important and, as of yet, unappreciated result. 
shown that masses and oak trees can be of different kinds. They can be of different kinds because Locke clearly thought that masses and oaks have different persistence conditions and a difference in kind can be maintained so long as there is some difference in the nominal essences associated with masses and oak trees.

To put it more clearly, there is some feature $\mathrm{p}$ that the mass, $\mathrm{M}$, outside my window has that the oak, $\mathrm{O}$, constituted by $\mathrm{M}$ lacks, namely, its persistence conditions. And so $\mathrm{M}$ and $\mathrm{O}$ do not have all the same features. The features in which they differ, their respective persistence conditions, are included in the nominal essences of mass and oak tree, and so $\mathrm{M}$ falls under the kind, mass, and not oak whereas $\mathrm{O}$ falls under oak and not mass. And so, given Locke's principle that things of different kinds can be in the same place at the same time, in the case of the mass and the oak tree constituted by it, it can be true that the oak tree constituted by mass $M_{1}$ at time $t_{1}$ is the very same oak tree as the one constituted by mass $M_{2}$ at time $t_{2}$, where $M_{1}$ is not identical to $\mathrm{M}_{2}{ }^{27}$ In other words, I can save the appearances with which I began the essay from within a Lockean framework and thereby solve the Kinds Problem.

There are two things to notice about Locke's theory of nominal essences that make it seem at least possible that the persistence conditions of a thing could be included in its nominal essence. The first thing to notice is that Locke does not hold that all features of a nominal essence are non-relational, or intrinsic, features of the entity or entities picked out by the word that stands for that nominal essence. ${ }^{28}$ A straightforward example that Locke

27 'For we never finding, nor conceiving it possible, that two things of the same kind should exist in the same place at the same time, we rightly conclude, that whatever exists any where at any time, excludes all of the same kind, and is there it self alone' ( $E$ II.xxvii.1).

${ }^{28}$ The non-relational/relational distinction (or the intrinsic-extrinsic distinction) is famously resistant to analysis. But it seems that I have some of my properties purely in virtue of the way I am-e.g. my mass; these are non-relational properties. And I have other properties in virtue of the way I interact with the world-e.g. my weight; these are relational properties. 
provides of a purely relational, or extrinsic, feature being included in a nominal essence is the case of the sun; Locke says that the sun's being 'at a certain distance from us' is part of its nominal essence ( $E$ II.xxiii.6). ${ }^{29}$ Obviously, the sun's being a certain distance from us involves a certain relation between the sun and us, and so clearly purely relational features of this kind can be included in nominal essences.

Indeed, Locke very frequently includes relational features in nominal essences. Consider the case of powers. Locke claims that 'Powers make a great part of our complex Ideas of Substances', and for Locke, 'Power includes in it some kind of relation', namely, at least in ordinary cases, a relation between something with an active power (a power to do something) and something with a passive power (a power to undergo something) ( $E$ II.xxiii.8, II.ii.3). In other words, Locke accepts that the nominal

Locke spends a chapter of the Essay (2.25) on relations and what he says is helpful. At a very basic level he says that non-relational features are those that involve considering things 'as they are in themselves' (Essay 2.25.1) or as 'something absolute in the Subject' (Essay 2.25.3). On the other hand, '[ $t]$ he nature... of Relation, consists in the referring, or comparing two things, one to another' (Essay 2.25.5). (For those interested in the modern discussion, see Weatherson and Marshall (2014).)

${ }^{29}$ Although Locke does not use the term 'nominal essence' in this passage, it seems clear that that is what he has in mind. For at the beginning of the section, without using the terms, Locke makes use of the distinction between a real essence and a nominal essence, saying, 'all the Ideas we have of particular distinct sorts of Substances, are nothing but several Combinations of simple Ideas, co-existing in such, though unknown, Cause of their Union, as makes the whole subsist of itself' (Essay 2.23.6). The real essence is the 'unknown Cause' in question and 'the Ideas' in question are nominal essences. It seems especially difficult to deny that the relevant Ideas mentioned in that section are nominal essences when one compares that passage to others in the Essay-e.g. at Essay 3.6.6, where Locke says that he calls the 'abstract Ideas of [Substances]...their nominal Essence'. What is more, it isn't as though the sun is treated as an importantly different case in this context. It appears on a list of what clearly seem to be standard examples of nominal essences: 'Man, Horse, Sun, Water, Iron' (Essay 2.23.6). So it seems that, indeed, Locke includes the sun's being 'at a certain distance from us' in the nominal essence Sun. Admittedly, the nominal essence Sun is a bit of an odd case, since it includes this sort of purely relational feature and not just qualities or powers. But for present purposes, what matters is not how often purely relational features are included in nominal essences, but only that Locke doesn't categorically exclude purely relational features from nominal essences. And this single example is enough to demonstrate that he doesn't categorically exclude purely relational features from nominal essences. 
essences of substances frequently include relational features of those substances. For example, part of the nominal essence of Fire is the power "which it has to change the colour and consistency of Wood' ( $E$ II.xxiii.7).

Of course, it is not at all surprising that relational features of entities can be included in the nominal essences of things given Locke's theory of secondary qualities, according to which: 'The sensible secondary Qualities, which depending on these, are nothing but the Powers, those Substances have to produce several Ideas in us by our Senses; which Ideas are not in the things themselves, otherwise than as any thing is in its Cause' $(E$ II.xxiii.9). So although the internal structure in virtue of which things have their sensible qualities are non-relational features of those entities, whenever a color, sound, smell, et cetera is included in a nominal essence, a relational feature of the thing has been included in its nominal essence. As a final example, consider the nominal essence of Swan and the slew of secondary qualities and powers included therein: 'white Colour, long Neck, red Beak, black Legs, and whole Feet, and all these of a certain size, with a power of swimming in the Water, and making a certain kind of Noise' ( $E$ II.xxiii.14). So it should be clear that Locke thinks that relational features of things are frequently included in their nominal essences.

However, it seems that this feature of Locke's discussion alone won't get one very far in dealing with the cases in which I'm interested, namely, cases like the case of the mass and the oak tree it constitutes. For it still isn't entirely clear how in cases like that there could be a divergence in the relational properties of the mass and the oak tree. This takes us to the second thing to notice about Locke's theory of nominal essences: among the relational features that can be considered relevant to a thing's nominal essence are relational features that are not observable at a single moment in time. That is, some of these features can only be discovered through observation over an extended period of time and yet they are still included in nominal essences. 
Consider the example of gold. ${ }^{30}$ Locke says that part of the nominal essence of gold is 'its Solubility in Aqua Regia' (Essay III.vi.6) ${ }^{31}$ Clearly gold's passive power to dissolve in aqua regia (a mixture of nitric and hydrochloric acids) requires an extended period of time in order to occur and thus it requires an extended period of time to observe. So in the case of gold a relational feature of it that requires a period of time to be observed is included in its nominal essence. ${ }^{32}$

Now, with this in mind, consider the claim that, given Locke's view of kinds, there is no way for the mass and the oak tree it constitutes at a time to be of different kinds, if the mass, M, and oak, $\mathrm{O}$, are thought to differ out in the world: the argument is that, because $\mathrm{O}$ and $\mathrm{M}$, which constitutes it at a time, have numerically identical internal constitutions, $\mathrm{M}$ and $\mathrm{O}$ cannot differ with respect to their observable features. And because observable features are the ingredients in nominal essences, the nominal essences that apply to $\mathrm{O}$ and $\mathrm{M}$ cannot differ because if $\mathrm{O}$ falls under a nominal essence so too will $\mathrm{M}$ and vice versa. If that is so, then the mass and the oak tree cannot be of different kinds.

The preceding discussion opens up room to object to this line

30 There are other examples, of course. Here are two: loadstones and opium. According to Locke, 'Hardness, Friability, and Power to draw Iron, we say, are Qualities to be found in a Loadstone' ( $E$ II.xxiii.3). Of course, the power to draw iron is a relational property. And it also is the sort of property that requires a duration in order to be observed; that is, we cannot observe iron being drawn towards a loadstone at an instant. So here too we have a case in which a relational feature that is not observable at an instant is included in a nominal essence.

Consider also the case of opium. Locke says that 'the Colour and Taste of Opium, are, as well as its soporifick or anodyne Virtues, meer Powers depending on its primary Qualities' (E II.xxiii.8). It seems clear that opium's soporific power is also a relational feature of opium that can only be observed over a period of time, and yet it is included in the nominal essence of opium. So, for Locke nothing in principle keeps some relational feature of a thing that is observable only over a temporal interval from being a part of the nominal essence of that thing.

${ }^{31}$ See also, E II.xxiii.37.

32 The point here is not that the disposition underlying gold's passive power to dissolve in aqua regia is itself extended in time. But rather the point is that some features (such as dispositions) that are included in nominal essences can only be observed and discovered over some stretch of time. 
of reasoning. From the fact that the oak tree and the mass constituting it have numerically identical internal constitutions at a time it does not follow that they must be alike with respect to the sorts of observable features relevant to nominal essences. For the observable features relevant to nominal essences may only be recognizable over time, rather than at an instant. We saw that it was actually the case that Locke included features only observable over time in his descriptions of the nominal essence of gold, and so we know that it is consistent with Locke's view to include such a feature. But is there any good candidate for a feature recognizable only over time that might be included in the nominal essences of the oak tree and/or the mass constituting it so as to place them in distinct kinds?

I believe that there is, namely, the respective persistence conditions of masses and oak trees. ${ }^{33}$ There is no need to bar persistence conditions from inclusion on the grounds that they are, on Locke's account, relational in character. ${ }^{34}$ For we have seen that relational features are included in nominal essences.

But not only are the relevant persistence conditions not barred from inclusion, they also seem to be a good candidate. Note that Locke is very clear that the persistence conditions of the mass and the oak tree differ. At II.xxvii.3, he says, "whilst [Atoms] exist united together, the Mass, consisting of the same Atoms, must be the same Mass, or the same Body, let the parts be never so differently jumbled: But if one of these Atoms be taken away, or one new one added, it is no longer the same Mass, or the same Body'. So a mass persists so long as all the atoms that make it up remain united and no new atoms are added to it. But a plant, like an oak tree, 'continues to be the same Plant, as long as it partakes of the same Life, though that Life be communicated to new Particles of Matter' (II.xxvii.4). So an oak will persist so long as it shares in a single vegetative life, whether particles are added or

${ }^{33}$ In footnote 36 , I consider and reject another candidate that has been suggested to me, namely, the power to propagate.

${ }^{34} E$ II.xxvii.1. The idea of identity is formed 'when comparing any thing as existing at any determin'd time and place, we compare it with it self existing at another time'. 
lost, whereas a mass can endure no change in the particles that constitute it. In other words, Locke thinks that masses and oaks have different persistence conditions.

One might be worried that persistence conditions aren't, in the relevant sense, observable. It is clear that they must be observable at least in the minimal sense that one could form an idea of those conditions on the basis of one's observations of the relevant phenomena. After all, as we have seen, 'we come to have the Ideas of particular sorts of Substances, by collecting such Combinations of simple Ideas, as are by Experience and Observation of Men's Senses taken notice of to exist together' ( $E$ II.xxiii.3). In other words, the simple ideas that are candidates for inclusion in nominal essences, at least with respect to material substances, are formed on the basis of one's experiences and observations. Now, although in the most frequently occurring cases, Locke holds that the process of gaining and losing atoms occurs 'insensibly', in a number of cases, like the case of a tree growing, or a horse that is 'sometimes fat, sometimes lean', it is clear that the mass that exists today is not the same as the one that existed in the past (II.xxvii.3). And, as there are clear cases of a gain and loss of particles, so too there also seem to be clear cases of a plant's continuing to live or ceasing to live. So it seems clear we observe change and its absence in our observations of things of this sort, at least in gross cases. And so it seems possible, by observation, to come to these two ideas of persistence, the one pertaining to masses and the other to oaks, even if we struggle to judge in any particular case whether, in fact, some set of persistence conditions is satisfied (e.g. whether the mass outside my window is now the same mass). And for the purposes of inclusion in a nominal essence, again, persistence conditions only need to be observable in the sense that one could form an idea of those conditions on the basis of one's observations of the relevant phenomena.

It seems that Locke himself recognized that the persistence conditions of masses and oaks were good candidates for inclusion in their respective nominal essences because he seems to have included them. And it seems that it was this difference in 
persistence conditions that served as Locke's basis for distinguishing masses and the oaks they constitute. For he says, 'wherein an Oak differs from a Mass of Matter... seems to me to be in this: that the one is only the Cohesion of Particles of Matter any how united, the other such a disposition of them as constitutes the parts of an Oak; and such an organization of parts, as is fit to receive and distribute nourishment so as to continue, and frame the Wood, Bark, and Leaves, etc. of an Oak, in which consists the vegetable Life' ( $E$ II.xxvii.4). Locke goes on immediately to lay out the persistence conditions of an oak tree, in terms of a shared Life. So, in this passage, Locke seems to be suggesting that an oak tree and the mass constituting it differ only in that the mass remains the same mass so long as all the particles of matter remain 'any how united' while the oak remains the oak so long as its successive stages share in one common life. That is, he seems to be drawing attention to the persistence conditions of oak trees and masses to explain how an oak tree and a mass differ in kind, even though at any given time the oak and the mass constituting it will share all and only the same particles.

There also seems to be general support for the idea that the persistence conditions of at least some things are contained in the nominal essences of those things in the passage quoted above:

'Tis not therefore Unity of Substance that comprehends all sorts of Identity, or will determine it in every Case: But to conceive and judge of it aright, we must consider what Idea the Word it is applied to stands for: It being one thing to be the same Substance, another the same Man, and a third the same Person, if Person, Man, and Substance, are three Names standing for three different Ideas; for such as is the Idea belonging to that Name, such must be the Identity ( $E$ II.xxvii.7)

Here it seems that Locke is suggesting that to know whether something is the same from one time to the next we have to consult our idea of the thing(s) in question. His examples are all general ideas: Person, Man, Substance. We have already seen that, in Locke, every general idea is a nominal essence. So this passage suggests that the persistence conditions of things that fall under at least some terms are included in the nominal essences 
associated with those terms. If not, why would he think that focusing on these ideas would help us get clear on the different identity conditions? It seems he must think that facts about persistence are built into those ideas. But this raises a possible worry. ${ }^{35}$ If persistence conditions are built into at least some nominal essences, don't those nominal essences simply determine the persistence conditions of the things that fall under those kinds? After all, something must determine their persistence conditions. Presumably it is essence that does so, and so it must be either real essences or nominal essences. But it can't be real essences, since e.g. they're unknowable. So it must be nominal essences.

The claim that nominal essences determine the persistence conditions of the things that fall under those kinds seems too strong, at least in the case of material things. This is so for the same basic reason that it seems too strong to say that the nominal essence gold determines that the things that fall under that kind dissolve in aqua regia. What is included in a nominal essence of a material thing is constrained by the way the world is inasmuch as a set of observable traits provides the raw material includable in a nominal essence, even when it comes to persistence conditions. That said, in the case of persistence conditions, the relationship between what is observed and what is included in the nominal essence is clearly less direct than in a case like aqua regia and gold. An example may help to see how the world might indirectly both provide and constrain the persistence conditions associated with a particular nominal essence. And, indeed, it is Locke himself, who provides the example of how this might go.

Locke sets about determining the appropriate persistence conditions to ascribe to oaks, by first reflecting on what it is to be an oak at a particular time - that is, by reflecting on the class of shared features had at a time that we might associate with Oak. As we have seen, he says, an oak is 'such a disposition of [particles of matter] as constitutes the parts of an Oak; and such an Organization of those parts, as is fit to receive, and distribute

\footnotetext{
${ }^{35}$ I owe this objection to an anonymous referee at Locke Studies.
} 
nourishment, so as to continue, and frame the Wood, Bark, and Leaves, etc. of an Oak, in which consists the vegetable Life' (II.xxvii.4). From these features associated with Oak, features which are themselves constrained by the raw material of the world, he settles on which of them provides the starting point for determining the persistence conditions of oak trees.

He settles on life: 'That being then one Plant, which has such an Organization of Parts in one coherent Body, partaking of one Common Life, it continues to be the same Plant, as long as it partakes of the same Life, though that Life be communicated to new Particles of Matter vitally united to the living Plant' (II.xxvii.4). So, as Locke thinks of it, a nominal essence doesn't straightforwardly determine persistence conditions, independently of any constraints. Rather, certain persistence conditions are included in a nominal essence on the basis of the same basic sort of process whereby less exotic features are included in nominal essences - experience, observation, and reflection on salient traits of things out there in the world. The process, however, is less direct in the case of persistence conditions inasmuch as features already included in the nominal essence seem to play an important role in drawing attention to traits that are potentially salient for a thing's persistence.

In sum, then, at the very least it seems that including the persistence conditions of oak trees and masses in nominal essences was, in principle, available to Locke, in which case Locke's views need not be inconsistent. What is more, I have given some reason to think that a stronger conclusion is warranted: that Locke does indeed accept the notion that the persistence conditions of oak trees and masses are included in their respective nominal essences and so Locke himself includes a feature in the nominal essences, mass and oak tree, that allows for a difference of kind between the two. In either case, the conclusion that Locke's views on kinds cannot be made consistent with his views on the oak-mass case can be avoided. ${ }^{36}$

${ }^{36}$ In conversation, Martha Brandt Bolton has suggested there may be another, better candidate feature that is recognizable only over time that might be included in the nominal essence, oak tree, and not mass, namely, the power to propagate. Certainly, the 


\section{\$4. Conclusion}

If the solution I have advocated for in this essay is correct, it seems that the Kinds Problem cannot get off the ground. For, if I am correct, a key premise that generates the problem is false. It isn't the case that, if at a time two things, $x$ and $y$, have the same internal constitution, $\mathrm{x}$ and $\mathrm{y}$ cannot differ in kind. For Locke accepts that relational features only observable over time can be included in nominal essences. Persistence conditions are this sort of feature. And so there is nothing to keep us from saying that Locke could-or perhaps did-maintain that the persistence conditions of at least things like masses and oak trees are included in the nominal essences, mass and oak tree. And, of course, if the persistence conditions of two things, $x$ and $y$, are included in the nominal essences of $\mathrm{x}$ and $\mathrm{y}$, then, if $\mathrm{x}$ and $\mathrm{y}$ have different persistence conditions, then $\mathrm{x}$ and $\mathrm{y}$ can have the same internal constitution at a time and still belong to different kinds-

power to propagate cannot be observed at a time. And the power to propagate is something that very plausibly belongs to the kind, oak, and not the kind, mass.

However, I have a worry about this proposal: the power to propagate doesn't seem to be a feature that could, ultimately, explain a difference in kind at a time and that is precisely what we need to do in order to avoid the Kinds Problem.

Take a mass, $\mathrm{M}$, and an oak, $\mathrm{O}$, that share an internal structure at a time. In order to avoid the Kinds Problem, at a time, $\mathrm{M}$ must fall under a kind that $\mathrm{O}$ doesn't, or vice versa. In order for that to be possible, $\mathrm{M}$ or $\mathrm{O}$ must have a feature that the other lacks. Now, whatever the power to propagate is, when had at a time, it apparently must be generated by the internal structure of that which has it. But if that's right, then $\mathrm{M}$ and $\mathrm{O}$ either both have the power to propagate or they both lack it, since they share a numerically identical internal structure. So, even if the power to propagate is included in the kind, oak, both $\mathrm{M}$ and $\mathrm{O}$ will fall under that kind in the cases we're interested in. And so the power to propagate cannot explain a difference in kind at a time and, again, that is precisely what we need to do in order to avoid the Kinds Problem.

Notice now that the same issue doesn't arise if the relevant feature is the persistence conditions. Take a mass, $\mathrm{M}_{2}$, and an oak, $\mathrm{O}_{2}$, that share an internal structure at a time: say, $t_{2}$. Assuming particles are added or lost between $t_{1}$ and $t_{2}$, then $M_{2}$ at $t_{2}$ does not bear the diachronic identity relation to $\mathrm{M}_{1}$ at $\mathrm{t}_{1}$. And assuming that a single Life is shared across $t_{1}$ and $t_{2}$, then $\mathrm{O}_{2}$ at $t_{2}$ does bear the diachronic identity relation to $\mathrm{O}_{1}$ at $\mathrm{t}_{1}$. In other words, although at a time $\mathrm{M}_{2}$ and $\mathrm{O}_{2}$ share an internal structure, they do not bear the same relations to their predecessors. As such, at $t_{2}$ sense can be made of the idea that the oak has a feature that the mass lacks: it bears a diachronic identity relation to $\mathrm{O}_{1}$ that $\mathrm{M}_{2}$ does not bear. And so we can explain how $\mathrm{O}_{2}$ and $\mathrm{M}_{2}$ can be of different kinds, despite sharing an internal structure at a time. 
where 'kinds' refers to nominal essences.

But one might have a general worry with this solution. It seems that on the approach that I'm ascribing to Locke, facts about persistence are thought to give rise to differences in ideas that are then drawn upon to solve problems about persistence. Isn't there some sort of vicious circularity here? I think not. If the Nominal Essence reading is correct, it seems that masses and oaks are, out in pre-sorted nature, different in some important sense. ${ }^{37}$ We recognize this important difference through observation and so we come to have different general ideas that capture how they differ out in the world. The important difference we latch onto, Locke seems to suggest, is that what it takes for a mass to be the same from one moment to the next is different from what it is for an oak to be the same from one moment to the next. That is, we grasp the difference between their respective persistence conditions and so recognize that masses and oaks are importantly different.

This important difference between the persistence conditions of each is enough to solve a kind of problem related to the oakmass case, namely, how can the mass and oak be of different kinds and so be in the same place at the same time? This important difference in pre-sorted nature between masses and oaks makes it possible to affirm that masses and oaks are of different kinds, which allows us to affirm that at a time a mass, $\mathrm{M}$, and an oak constituted by it, $\mathrm{O}$, are importantly different, and so, in an important sense, distinct individuals.

So, according to this solution, it is not that we arbitrarily assign different persistence conditions to masses and oaks and then that assigned difference is appealed to in order to establish that masses and oaks can be in the same place at the same time. Rather, the

37 Again, this is an important respect in which the Nominal Essence reading is connected to a different background picture of the mass-oak case than, say, the Material-Immaterial Substance reading. As it has been defended in the literature, the Nominal Essence reading is deeply connected to the coincident object reading of the mass-oak case-see Kaufman (2007). It should also be noted that, if the four dimensionalist reading of the mass-oak case is correct, masses and oaks are, out in presorted nature, different in some important sense. It is only on the relative identity reading of the mass-oak case that this claim will seem mistaken. 
fact that the persistence conditions of masses differ from those of oaks in pre-sorted nature provides the basis both for recognizing the persistence of masses and oaks and for picking oaks and masses out as importantly different at a time. So there is no vicious circularity here.

I have argued that Locke's theory of kinds can be squared with the Nominal Essence reading of his Place-Time-Kind Principle. The general solution that I have advocated at least seems open to Locke, given his treatment of nominal essences, his examples, and his explanation of the mass-oak case in particular. And, indeed, it seems that Locke himself may have adopted all the essentials of this solution. It turns out, then, that the Kinds Problem isn't a problem for Locke, and so the Nominal Essence reading should not be rejected on the grounds that it leaves Locke's views unnecessarily inconsistent. For he has given us the means for a solution, one on which relational features observable only over time play an important role in individuating objects.

This is an intriguing idea: individuation can be explained, at least at times, by an appeal to temporally extended features of individuals. It seems that this strategy may have interesting applications in other cases. Of course, one of the applications with which Locke seems most concerned is the case with which I began the essay. And it seems that, even on the Nominal Essence Reading, Locke has succeeded in putting us in a position to affirm that the stately oak outside my window, even having lost all its leaves and with them a host of particles, remains the same oak. ${ }^{38}$

\section{Humboldt-Universität zu Berlin}

${ }^{38}$ Many people provided helpful feedback on this essay at different stages. To start, I'd like to thank the organizers of the 2014 Locke Workshop, Benjamin Hill and Jessica Gordon-Roth, for the opportunity to present an early version of this paper. For their helpful comments, I would very much like to thank those who attended that workshop, including Kenneth Winkler, Patricia Sheridan, Ruth Boeker, Elliot Rossiter, Martha Brandt Bolton, Antonia LoLordo, Julie Walsh, Shelley Weinberg, and Edwin McCann. I would also like to thank Bob Pasnau for his feedback at various stages of writing and editing. And a very special thank you to Dan Kaufman, whose teaching and writing inspired this essay. 


\section{REFERENCES}

Anstey, Peter. 2015. 'John Locke and the Philosophy of Mind', Journal of the History of Philosophy 53: 221-44.

- Forthcoming. 'Newton and Locke'. In Chris Smeenk and Eric Schliesser (eds.). The Oxford Handbook of Isaac Newton. Oxford.

Bolton, Martha Brandt. 2014. 'Locke's Account of Substance in Light of his General Theory of Identity'. In Locke and Leibniz on Substance, ed. Paul Lodge and Tom Stoneham, 63-88. New York.

- 1994. 'Locke on Identity: the scheme of simple and compounded things'. In Individuation and Identity in Early Modern Philosophy: Descartes to Kant, ed. Kenneth F. Barber, 103-31. Albany, NY.

Broad, C. D. 1951. 'Locke's Doctrine of Substantial Identity \& Diversity', Theoria 17: 13-26.

Chappell, Vere. 1989. 'Locke and Relative Identity', History of Philosophy Quarterly 6: 69-83.

—. 1990. 'Locke on the Ontology of Matter, Living Things, and Persons', Philosophical Studies 60: 19-32.

Conn, Christopher. 1999. 'Two Arguments for Lockean FourDimensionalism', British Journal for the History of Philosophy 7: 42945.

_. 2002. 'Locke on Natural Kinds and Essential Properties', Journal of Philosophical Research 27: 475-497.

. 2003. Locke on Essence and Identity. Dordrecht.

Curley, Edwin. 1982. 'Leibniz on Locke on Personal Identity'. In Leibniz: Critical and Interpretive Essays, ed. Michael Hooker, 302-26. Minneapolis, MN.

—. 1972. 'Locke, Boyle, and the Distinction Between Primary and Secondary Qualities', Philosophical Review 81: 438-464.

Downing, Lisa. 2007. 'Locke's Ontology', In The Cambridge Companion to Locke's 'Essay Concerning Human Understanding', ed. Lex Newman, 352-80. Cambridge

Geach, Peter. 1967. 'Identity', Review of Metaphysics 21: 3-12.

Gordon-Roth, Jessica. 2015. 'Locke on the Ontology of Persons', Southern Journal of Philosophy 53: 97-123.

—. 2015. 'Locke's Place-Time-Kind Principle', Philosophy Compass 10: $264-74$.

Kaufman, Dan. 2007. 'Locke on Individuation and the Corpuscular Basis of Kinds', Philosophy and Phenomenological Research 75: 499-534.

Locke, John. 1824. A Letter to the Right Reverend Edward, Lord Bishop of Worcester. In The Works of John Locke, 9 vols., III, 1-96. London. 
. 1975. An Essay Concerning Human Understanding, ed. Peter H. Nidditch. Oxford.

LoLordo, Antonia. 2012. Locke's Moral Man. Oxford.

—. 2010. 'Person, Substance, Mode, and 'the Moral Man' in Locke's Philosophy', Canadian Journal of Philosophy 40: 643-68.

Losonsky, Michael. 2007. 'Language, Meaning, and Mind in Locke's Essay'. In Newman (ed.). The Cambridge Companion to Locke's 'Essay', 286-312. Cambridge.

McCann, Edwin. 'Essences and Kinds of Substance'. Paper presented at Locke Workshop. City University of New York, Lehman College. March 18, 2014.

—. 1987. 'Locke on Identity: Matter, Life, and Consciousness', Archiv fur Geschichte der Philosophie 69: 54-77.

- 2008. 'Identity, Essentialism, and the Substance of Body in Locke'. In Contemporary Perspectives on Early Modern Philosophy: Essays in Honor of Vere Chapell, ed. Paul Hoffman, David Owen, \& Gideon Yaffe, 173-90. Peterborough, ON.

Noonan, Harold. 1978. 'Locke on Personal Identity', Philosophy 53: 343353.

Oderberg, David. 1996. 'Coincidence Under a Sortal', The Philosophical Review 105: 145-71.

Stuart, Matthew. 2013. Locke's Metaphysics. Oxford.

—. 2013. 'Revisiting People and Substances'. In Debates in Modern Philosophy: Essential Readings and Contemporary Responses, ed. Stewart Duncan and Antonia LoLordo, 186-96. New York.

Thiel, Udo. 2011. The Early Modern Subject: Self Consciousness and Personal Identity from Descartes to Hume. Oxford.

- 1998. 'Individuation'. In The Cambridge History of Seventeenth Century Philosophy, 2 vols., ed. Michael Ayers and Daniel Garber, II, 212-62. Cambridge.

Uzgalis, William. 1990. 'Relative Identity and Locke's Principle of Individuation', History of Philosophy Quarterly 7: 283-297.

Weatherson, Brian and Dan Marshall. 2014. 'Intrinsic vs. Extrinsic Properties'. In The Stanford Encyclopedia of Philosophy, ed. Edward N. Zalta. <http://plato.stanford.edu/archives/fall2014/entries/intrinsicextrinsic/>.

Winkler, Kenneth. 1991. 'Locke on Personal Identity', Journal of the History of Philosophy 29: 201-26.

Wiggins, David. 1968. 'On Being in the Same Place at the Same Time', The Philosophical Review 77: 90-95. 
Yaffe, Gideon. 2007. 'Locke on Ideas of Identity and Diversity'. In Newman (ed.), The Cambridge Companion to Locke's 'Essay', 192230. Cambridge. 